\title{
Targeted deletions of complement lectin pathway genes improve outcome in traumatic brain injury, with MASP-2 playing a major role
}

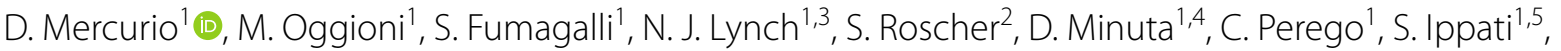 \\ R. Wallis², W. J. Schwaeble ${ }^{3}$ and M.-G. De Simoni ${ }^{1 *}$ (1)
}

\begin{abstract}
The lectin pathway (LP) of complement activation is believed to contribute to brain inflammation. The study aims to identify the key components of the LP contributing to TBI outcome as possible novel pharmacological targets. We compared the long-term neurological deficits and neuropathology of wild-type mice (WT) to that of mice carrying gene deletions of key LP components after experimental TBI. WT or MASP-2 (Masp2 $\left.{ }^{-/-}\right)$, ficolin-A (FCna $\left.{ }^{-/-}\right), \mathrm{CL}-11$ (Colec $\left.11^{-/-}\right)$, MASP-1/3 (Masp1 $\left.{ }^{-/-}\right)$, MBL-C (Mbl2 $\left.{ }^{-/-}\right)$, MBL-A $\left(\mathrm{Mbl}^{-/-}\right)$or $\mathrm{MBL}^{-1-}\left(\mathrm{Mbl}^{-/-} / \mathrm{Mbl}^{-/-}\right)$deficient male C57BL/6J mice were used. Mice underwent sham surgery or TBI by controlled cortical impact. The sensorimotor response was evaluated by neuroscore and beam walk tests weekly for 4 weeks. To obtain a comparative analysis of the functional outcome each transgenic line was rated according to a health score calculated on sensorimotor performance. For selected genotypes, brains were harvested 6 weeks after injury for histopathological analysis. MASP$2^{-/-}, \mathrm{MBL}^{-/-}$and FCN-A ${ }^{-/-}$mice had better outcome scores compared to WT. Of these, MASP-2 ${ }^{-1-}$ mice had the best recovery after TBl, showing reduced sensorimotor deficits (by $33 \%$ at 3 weeks and by $36 \%$ at 4 weeks). They also showed higher neuronal density in the lesioned cortex with a 31.5\% increase compared to WT. Measurement of LP functional activity in plasma from MASP- $2^{-/-}$mice revealed the absence of LP functional activity using a C4b deposition assay. The LP critically contributes to the post-traumatic inflammatory pathology following TBI with the highest degree of protection achieved through the absence of the LP key enzyme MASP-2, underlining a therapeutic utility of MASP-2 targeting in TBI.
\end{abstract}

Keywords: Traumatic brain injury, Neuroinflammation, Lectin pathway, Complement cascade, MBL-associated serine protease, Neurological deficits, Pharmacological target

\section{Introduction}

Traumatic brain injury (TBI) is associated with a primary biomechanical injury that can involve contusion and laceration, diffuse axonal injury, brain swelling and intracranial haemorrhage [1-3] followed by a secondary injury, which is caused by the activation of several molecular and

*Correspondence: desimoni@marionegri.it

1 Department of Neuroscience, Istituto di Ricerche Farmacologiche Mario Negri IRCCS, via Mario Negri 2, 20156 Milan, Italy

Full list of author information is available at the end of the article cellular cascades contributing to brain damage and its development over time [4-6]. Secondary insult response typically includes blood-brain barrier (BBB) breakdown, oxidative stress, glutamate excitotoxicity, and neuroinflammation [7-9]. Since the secondary damage evolves days after the impact, there are windows of opportunity for pharmacological therapeutic intervention.

The complement system, an important component of the innate and adaptive immune response, is a major coordinator of post-traumatic neuroinflammation and secondary neuropathology after TBI [10-14]. Even in original author(s) and the source, provide a link to the Creative Commons licence, and indicate if changes were made. The images or other third party material in this article are included in the article's Creative Commons licence, unless indicated otherwise in a credit line to the material. If material is not included in the article's Creative Commons licence and your intended use is not permitted by statutory regulation or exceeds the permitted use, you will need to obtain permission directly from the copyright holder. To view a copy of this licence, visit http://creativecommons.org/licenses/by/4.0/. The Creative Commons Public Domain Dedication waiver (http://creativeco mmons.org/publicdomain/zero/1.0/) applies to the data made available in this article, unless otherwise stated in a credit line to the data. 
absence of infection (which can be an additional complication following TBI) the complement system can be activated by endogenous danger signals called damageassociated molecular patterns (DAMPs) [15]. Depending on the signals, complement activation may occur through three different pathways, the classical, the alternative and the lectin pathway (LP), each composed of specific initiators and effector enzymes. Carbohydrate structures or acetylated proteins exposed on the surface of damaged cells, including apoptotic or necrotic cells and stressed endothelium [16], are typical DAMPs recognized by the LP. Recognition of these signals by initiator molecules leads to activation of the associated serine proteases MASPs (MBL-associated serine proteases) and subsequent activation of the complement cascade.

There is a growing body of evidence showing that LP activation critically contributes to disease severity in acute brain injury. Genetic deletion of LP subcomponents (MBL or MASP-2) [17-19] or their pharmacological targeting $[17,18]$ are protective in experimental models of brain ischemia. In addition to its role as an LP initiator, the recognition subcomponent MBL was shown to possess direct activity, driving platelet-dependent inflammation and vascular damage following ischemic injury $[16,20]$. Of note, TBI shares blood perfusion deficits and metabolic derangements with ischemic injury [21], thus suggesting that similar mechanisms might be involved in the traumatic pericore tissue [22], an area subjected to post-injury hypoxia [23].

In human TBI contusions, the LP recognition molecules (MBL, ficolin-1, ficolin-2, ficolin-3 and CL-11/ CL-10) and the enzymes MASP-2 and MASP-3 have been found deposited inside and outside the cerebral vessels. Importantly, MBL, ficolin-2 and ficolin-3 levels are elevated in the brains of TBI compared to non-TBI patients and perivascular MASP-2 deposition increase with injury severity [23]. These results demonstrate the involvement of the LP in TBI pathology, although the specific recognition molecules or enzymes which most prominently contribute to the TBI sequelae remain elusive. The comparative analysis shown here, identifies novel targets for therapeutic intervention, aiming to reduce post traumatic inflammatory responses, brain tissue loss, and to ameliorate loss of cognitive function following TBI. In this study, we compared the neurobehavioral outcome and health score up to 4 weeks after TBI of wild-type (WT) mice and of mice knocked-out for MASP-2 $\left(\mathrm{Masp}^{-l-}\right)$, ficolin-A $\left(F c n a^{-l-}\right)$, CL-11 (Colec11 $\left.{ }^{-1-}\right)$, MASP-1/3 $\left(\right.$ Masp $\left.^{-1-}\right)$, MBL-C $\left(\mathrm{Mbl2}^{-/-}\right)$, MBL-A $\left(\mathrm{Mbl1}^{-1-}\right)$ or $\mathrm{MBL}^{-1-}\left(\mathrm{Mbl1}^{-1-} / \mathrm{Mbl2}^{-1-}\right)$. Our results demonstrate that MASP-2 deficiency brings the highest protective phenotype, countering long-term neuroinflammatory injury following TBI, as shown by reduced neuronal deficits and neuronal cell loss compared to wild-type mice. $\mathrm{MBL}^{-1-}$ and $\mathrm{FCN}-\mathrm{A}^{-1-}$ mice were also significantly protected and presented good outcome scores, indicating that these molecules might be relevant initiators of the inflammatory response to TBI.

\section{Methods \\ Mice}

Procedures involving animals and their care were conducted in conformity with institutional guidelines in compliance with national and international laws and policies (prot.9F5F5.81 authorisation $n^{\circ} 753 / 2017-P R$ ). A total of $61 \mathrm{WT}$ and $57 \mathrm{KO}$ mice were studied. We used male 9 week old C57BL/6J mice weighing 22-28 g, either WT (purchased from Charles Rivers-Italy) or with targeted deletion of MASP-2, ficolin-A, CL-11, MASP-1/3 (Masp2 $^{-1-}$, Fcna $^{-1-}$, Colec11 ${ }^{-1-}$, Masp $^{-1-}$ Biomedical Services, University of Leicester) MBL-C and MBL-A, $\left(\mathrm{Mbl2}^{-1-}\right.$ and $\mathrm{Mbl1}^{-/-}$obtained at Mario Negri Institute by crossing $\mathrm{MBL}^{-1-}$ mice with WT mice and selecting appropriate colony founders). The protocols and details of this report are in accordance with ARRIVE guidelines (http://www.nc3rs.org.uk/page.asp?id=1357, check list provided as supplementary file).

\section{Experimental traumatic brain injury}

Mice were anesthetized with isoflurane inhalation (induction 5\%; maintenance 2\%) in an $\mathrm{N}_{2} \mathrm{O} / \mathrm{O}_{2}(70 / 30 \%)$ mixture and placed in a stereotactic frame. Mice were then subjected to craniotomy followed by induction of controlled cortical impact (CCI) brain injury as previously described [24-27]. Briefly, the injury was induced using a $3 \mathrm{~mm}$ diameter rigid impactor driven by a pneumatic piston rigidly mounted at an angle of $20^{\circ}$ from the vertical plane and applied vertically to the exposed dura mater, between bregma and lambda, over the left parietotemporal cortex. We set an impactor velocity of $5 \mathrm{~m} / \mathrm{s}$ and deformation depth $1 \mathrm{~mm}$, resulting in a severe level of injury $[28,29]$. The craniotomy was then covered with a cranioplasty and the scalp sutured. Sham-operated mice received identical anesthesia and surgery without craniotomy and brain injury.

\section{Behavioural tests}

Sensorimotor deficits were assessed by neuroscore and beam walk tests as described previously $[22,28,30] \mathrm{Neu}$ roscore Mice were scored from 4 (normal) to 0 (severely impaired) for each of the following: (1) forelimb function during walking on the grid and flexion response during suspension by the tail; (2) hindlimb function during walking on the grid and extension during suspension by the tail; (3) resistance to lateral right and left push. The best score is 12 . 
Beam walk The test measures the number of foot faults of the mouse walking twice on an elevated, narrow wooden beam ( $5 \mathrm{~mm}$ wide and $100 \mathrm{~cm}$ long). Before each test, mice are trained in three habituation trials. Data are expressed as the sum of the number of foot faults during the two tests. The best score is 0 .

\section{Tissue processing}

At 6 weeks after surgery, under deep anesthesia (Ketamine $20 \mathrm{mg}+$ Medetomidine $0.2 \mathrm{mg}$ ), animals were transcardially perfused with $30 \mathrm{~mL}$ of phosphate buffer saline (PBS) $0.1 \mathrm{~mol} / \mathrm{L}, \mathrm{pH} \mathrm{7.4}$, followed by $60 \mathrm{~mL}$ of chilled paraformaldehyde (4\%) in PBS. The brains were carefully removed from the skull and post-fixed for $6 \mathrm{~h}$ at $4{ }^{\circ} \mathrm{C}$, then transferred to $30 \%$ sucrose in $0.1 \mathrm{~mol} / \mathrm{L}$ phosphate buffer for $24 \mathrm{~h}$ until equilibration. The brains were frozen by immersion in isopentane at $-45^{\circ} \mathrm{C}$ for $3 \mathrm{~min}$ before being sealed into vials and stored at $-80{ }^{\circ} \mathrm{C}$ until use. Coronal brain $20 \mu \mathrm{m}$-thick cryosections were cut serially (from bregma $+1.2 \mathrm{~mm}$ to bregma $-4 \mathrm{~mm}$ ) at $200 \mu \mathrm{m}$ intervals and stained with Cresyl violet (Sigma-Aldrich) using standard histological protocols [26, 31].

\section{Contusion volume}

Eight coronal section from bregma +0.6 to $-4.0 \mathrm{~mm}$ were acquired with an Olympus BX-61 Virtual Stage microscope using a $2 \times$ objective lens, with a pixel size of $3.49 \mu \mathrm{m}$. Contusion volume was analysed as previously described [22].

\section{Neuronal count}

The neuronal cell count was performed at 6 weeks after TBI. Three $20 \mu \mathrm{m}$-thick coronal sections at $0.4,1.6$, and $2.8 \mathrm{~mm}$ posterior to bregma and stained with Cresyl violet (Sigma-Aldrich, St. Louis, MO) were selected from each mouse brain to quantify neuronal cell loss. The entire sections were acquired with an Olympus BX-61 Virtual Stage microscope using a $20 \times$ objective lens, with a pixel size of $0.346 \mu \mathrm{m}$. Acquisition was done over $10 \mu \mathrm{m}$ thick stacks, with a step size of $2 \mu \mathrm{m}$. The different focal planes were merged into a single stack by mean intensity projection to ensure consistent focus throughout the sample. Neuronal count was performed by segmenting the cells over a cortical region proximal to the lesion and in the corresponding contralateral hemisphere and excluding the round-shaped signal sized below the area threshold of $25 \mathrm{~mm}^{2}$ that is known to be associated with glial cells as reported previously [32]. Quantification was performed by Fiji software. Data were expressed as the total number of neurons quantified in the selected cortical region.

\section{Microglia and astrocyte immunohistochemical analysis}

Immunohistochemistry was performed on $20 \mu \mathrm{m}$-thick coronal sections from perfused mouse brains. The sections were incubated overnight at $4{ }^{\circ} \mathrm{C}$ with primary monoclonal antibody anti-mouse glial fibrillary acid protein (GFAP, $0.5 \mu \mathrm{g} / \mathrm{ml}$, Millipore, Billerica, MA, USA) or anti-mouse CD11b $(1.25 \mu \mathrm{g} / \mathrm{ml}$, Bio rad, Hercules, CA, USA). Biotinylated secondary antibodies $(7.5 \mu \mathrm{g} /$ $\mathrm{ml}$, Vector Laboratories) were used. GFAP and CD11b immunopositive cells were identified by reaction with 3,3 diaminobenzidine-tetrahydrochloride (DAB, Vector Laboratories, Burlingame, CA, USA) as previously described [33]. Negative control studies, without the primary antibody, were performed in parallel. Three $20 \mu \mathrm{m}$-thick coronal sections at $0.4,1.6$, and $2.8 \mathrm{~mm}$ posterior to bregma were selected from each mouse brain for GFAP and CD11b quantification. The entire sections were acquired with an Olympus BX-61 Virtual Stage microscope using a $20 \times$ objective lens, with a pixel size of $0.346 \mu \mathrm{m}$. Acquisition was done over $10 \mu \mathrm{m}$ thick stacks, with a step size of $2 \mu \mathrm{m}$. The different focal planes were merged into a single stack by mean intensity projection to ensure consistent focus throughout the sample. The ipsilateral cortex was analyzed over an area included within a $350 \mu \mathrm{m}$ radius from the contusion edge. Images were analyzed using Fiji software. GFAP and CD11b immunostained area were expressed as positive pixels/total assessed pixels and reported as the percentage of total stained area [28]. Microglia shape descriptor analysis was performed on image processed through the algorithm previously described [21]. Once segmented, the cells were measured for the following parameters: area, perimeter, circularity, Feret's diameter (max caliper), aspect ratio and solidity. Mean single-cell values for each parameter were used for statistics.

\section{MBL-C deposition in the brain}

The brain coronal sections were incubated overnight at $4{ }^{\circ} \mathrm{C}$ with primary monoclonal antibody anti-mouse MBL-C ( $1 \mu \mathrm{g} / \mathrm{ml}$; Hycult Biotechnology, Uden, The Netherlands) followed by a secondary biotinylated antibody against rat IgG. Positive cells were stained with Tyramide Cyanine 5 (Cy5, 1:300, Perkin Elmer, Milan, Italy). Cell nuclei were stained with 40-6-diamidino-2-phenylindole (Hoechst, $1 \mathrm{mg} / \mathrm{ml}$, Invitrogen, Carlsbad, CA). For negative control staining, the primary antibody was omitted, and no staining was observed. Three $20 \mu \mathrm{m}$-thick coronal sections at $0.4,1.6$, and $2.8 \mathrm{~mm}$ posterior to bregma were selected from each mouse brain for MBL-C quantification. Confocal microscopy was done with a Nikon A1 confocal scan unit with a $20 \times 0.5$ numerical aperture (NA) objective, managed by NIS elements software. Tissues were imaged at laser excitation of 405 (for nuclei) 
and 647 (for MBL-C) [34]. Image acquisition was done at 12-bit, keeping the fluorescent signal in a non-saturated range (0-1000 greyscale values). The acquisition was done over an area sized $2 \times 2.5 \mathrm{~mm}$, positioned in the ipsilateral hemisphere along the cortical region proximal to the lesion, with a pixel size of $0.62 \mu \mathrm{m}$. Acquisition was done over $8.3 \mu \mathrm{m}$ thick stacks, with a step size of $2.075 \mu \mathrm{m}$. The different focal planes were merged into a single stack by maximum intensity projection to ensure consistent focus throughout the sample. Immunostaining for MBL-C was quantified by assessing fluorescence intensity using Fiji software. To subtract the background signal, a minimum threshold was applied based in the highest grayscale value of background [28]. MBL-C signal was reported as fluorescence integrated density.

\section{Lectin pathway activity assay}

Lectin Pathway activation was quantified using the C4 cleavage assay developed by Petersen et al. [35]. The assay measures the ability of MASP-2 to cleave human $\mathrm{C} 4$ added in replacement of endogenous $\mathrm{C} 4$ which is inactivated. This procedure provides a clean measure of MASP-2 activity without interference from endogenous C4. Nunc MaxiSorb microtiter plates were coated with $100 \mu \mathrm{l}$ of mannan in coating buffer. After overnight incubation, wells were blocked with $0.1 \%$ human serum albumin (HSA) in TBS (10 mM Tris-Cl, $140 \mathrm{mM}$ $\mathrm{NaCl}, \mathrm{pH} 7.4$ ), then washed with TBS containing $0.05 \%$ Tween 20 and $5 \mathrm{mM} \mathrm{CaCl}_{2}$ (wash buffer). Plasma samples were diluted in $20 \mathrm{mM}$ Tris-Cl, $1 \mathrm{M} \mathrm{NaCl}, 10 \mathrm{mM}$ $\mathrm{CaCl}_{2}, 0.05 \%$ Triton X-100, 0.1\% HSA, pH 7.4, which prevents activation of endogenous $\mathrm{C}$. The diluted samples were added to the plate and incubated overnight at $4{ }^{\circ} \mathrm{C}$. The next day, the plates were washed thoroughly with wash buffer, then $0.1 \mu \mathrm{g}$ of purified human C4 [36] in $100 \mu \mathrm{l}$ of $4 \mathrm{mM}$ barbital, $145 \mathrm{mM} \mathrm{NaCl}, 2 \mathrm{mM} \mathrm{CaCl}_{2}$, $1 \mathrm{mM} \mathrm{MgCl}$, $\mathrm{pH} \mathrm{7.4,} \mathrm{was} \mathrm{added} \mathrm{to} \mathrm{each} \mathrm{well.} \mathrm{After} 1.5 \mathrm{~h}$ at $37{ }^{\circ} \mathrm{C}$, the plates were washed again, and $\mathrm{C} 4 \mathrm{~b}$ deposition was detected using alkaline phosphatase-conjugated chicken anti-human C4c (Immunsystem, Uppsala, Sweden) and the colorimetric substrate pNPP.

\section{Health score}

To obtain a comparative analysis of the functional outcome, each transgenic line was rated according to a health score calculated on sensorimotor performance, as shown previously [19]. The neuroscore and beam walk performance data sets obtained in WT mice (total number $=61$ ) were stratified into four groups according to quartiles. Each quartile was attributed a score ranging from 4 to 1 corresponding to the best to the worst outcome, respectively. Each mouse (including WT and $\mathrm{KO}$ ) obtains a final score which is the sum of the weighted scores of the two parameters, e.g. the neuroscore accounted for $50 \%$ and beam walk accounted for $50 \%$ of the final score. The effect size (odds ratio) was calculated by a Chi square test using the Woolf logit interval for computing the $95 \%$ confidence interval, stratifying mice in terms of good outcome (defined as a score $\geq 3$ ) versus bad outcome $($ score $<3)$. Odds ratios are reported in the forest plot and quantify the strength of the association between the genotype and the TBI outcome. Statistical analysis was performed with the standard software package GraphPad Prism (GraphPad Software Inc., San Diego, CA, USA, version 7.0); $p$ values lower than 0.05 were considered significant.

\section{Experimental design and additional statistics}

Mice were randomly allocated to surgery and assigned across cages and days. To minimize variability, all surgeries were performed by the same investigator. Subsequent behavioural, histological, immunohistological, and biochemical evaluations were performed blind by another investigator. Group size is of 14defined by the formula: $\mathrm{n}=2 \sigma^{2} \mathrm{f}(\alpha, \beta) / \Delta^{2}$ (SD in groups $=\sigma$, type 1 error $\alpha=0.02$, type II error $\beta=0.2$, percentage difference between groups $\Delta=20$ ). Standard deviation to be used in the formula for each assessment was calculated based on previous experiments with same outcome measures (e.g. behavioural deficits), resulting in $\sigma=16.9$ and $n=14.4$. To limit the use of animals, a post hoc power analysis test was done at $n=7$ on raw data for each experimental branch. The experiment was interrupted at $\mathrm{n}=7$ for MBL-C ${ }^{-1-}$ and MBL-A ${ }^{-1-}$ mice since it was unable to provide significant differences using a reasonable number of animals $(\Delta=3.89, \sigma=22.49$, thus expected $\mathrm{n}=668.37)$. For MASP- $2^{-1-}$ mice the experiment was interrupted at $\mathrm{n}=7$ since a significant difference was already in place due to a strong protective effect $(\Delta=17.76$ (3 week) $\Delta=19.4$ ( 4 week)).

Groups were compared by analysis of variance and post hoc testing as indicated in each figure legend. A parametric or nonparametric test was selected after the Kolmogorov-Smirnov test for normality to assess whether the data for the groups were normally distributed. The constancy of the variances was checked by the Bartlett test.

\section{Results \\ MASP-2 ${ }^{-1-}$ mice showed the best outcome after TBI with reduced sensorimotor deficits}

This study was conducted according to the plans depicted in Fig. 1a. Wild-type (WT) or KO mice (including: MASP-2 $2^{-1-}$, FCN-A ${ }^{-1-}, \mathrm{CL}-11^{-/-}, \mathrm{MBL}^{-\mathrm{C}^{-1-}}$, MASP$1 / 3^{-1-}$ and $\mathrm{MBL}-\mathrm{A}^{-/-}$) were subjected to TBI or sham injury. Sensorimotor deficits were assessed weekly for 4 weeks by neuroscore and beam walk tests. The data 
a injury on WT or
KOs mice

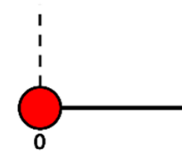

b

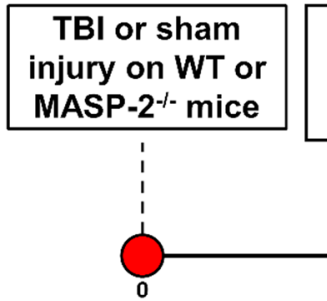

\section{Brain MBL presence and lectin pathway activity assay in plasma}

Neuroscore, Beam walk test
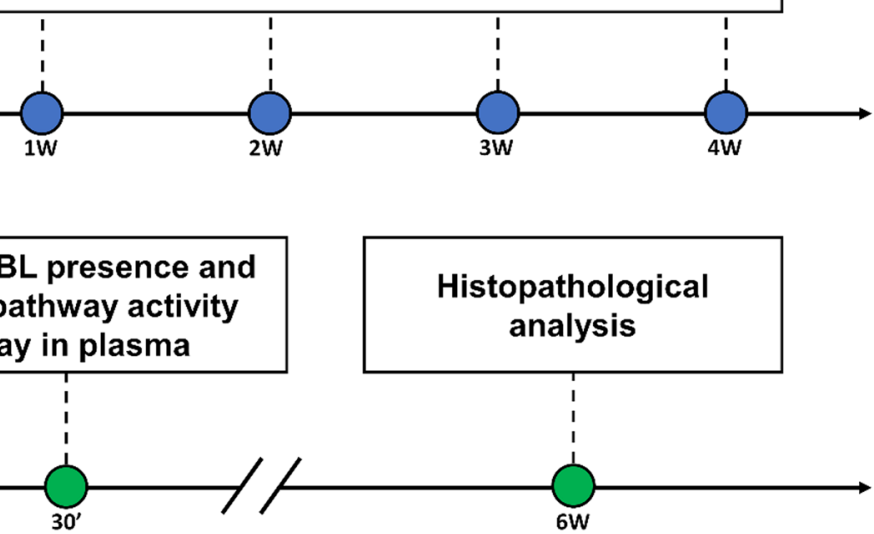

Histopathological analysis

Fig. 1 Experimental design. a WT or KOs mice (including: MASP-2 ${ }^{-/}, \mathrm{MBL}^{-/}, \mathrm{FCN}-\mathrm{A}^{-/-}, \mathrm{CL}-11^{-/-}, \mathrm{MBL}-\mathrm{C}^{-/-}, \mathrm{MASP}-1 / 3^{-/-}$and $\mathrm{MBL}-\mathrm{A}^{-/-}$) were subjected to TBI or sham injury. Sensorimotor deficits were assessed weekly by neuroscore and beam walk test. The sum of 4-week performances of each mouse genotype has been used to calculate the health score. $\mathbf{b}$ MBL brain presence and residual LP activity in plasma was assed in MASP-2 ${ }^{-/-}$ and WT TBI mice 30' after surgery. Histopathological analysis was done for MASP-2 ${ }^{-1-}$ and WT mice at 6 weeks after TBI

related to the sensorimotor performance are summarized in Table 1 . The health score and odds ratio data for $\mathrm{MBL}^{-1-}$ mice were calculated using previously published data from our lab [32]. To obtain a comparative evaluation of the transgenic lines, a health score based on the outcome of the two sensorimotor tests was calculated. Mice were rated from 1 (bad outcome) to 4 (good outcome, Fig. 2a).

MASP-2 ${ }^{-1-}$ was the most protective genotype, showing a positive association with a good outcome (odds ratio 56.3 [95\% CI 1.9-1655], $p=0.002) . \mathrm{MBL}^{-/-}$and FCN-A ${ }^{-1-}$ mice were also significantly protected, showing a positive association with a good outcome, but to a lesser extent than MASP- $2^{-/-}(p=0.0017$ and $p=0.0386$; odds ratio 36 [2.7-476.3] and 9.1 [0.9-92.4], respectively). CL- $11^{-/-}$and $\mathrm{MBL}-\mathrm{C}^{-/-}$genotypes showed a weaker, non-significant association with a good outcome $(p=0.0566$ and $p=0.5582$ respectively), whereas MASP- $1 / 3^{-1-}$ and MBL-A ${ }^{-1-}$ mice were not protected $(p=0.5570$ and $p=0.527$ respectively, Fig. $2 \mathrm{~b}$ ).

\section{MASP-2 ${ }^{-1-}$ mice had higher neuronal density than WT mice after TBI}

Based on the outcome data, we focused on the MASP$2^{-/-}$genotype and assessed the lesion size at 6 weeks (neuronal density, GFAP and CD11b immunostaining) and the degree of local brain inflammation at $30 \mathrm{~min}$ (presence of MBL-C in the brain and residual LP activity in plasma) (Fig. 1b). At 6 weeks post injury, we observed an extensive macroscopic area of cortical tissue loss, extending rostrocaudally from bregma +0.4 to $-3.6 \mathrm{~mm}$, both in WT and MASP-2 $2^{-1-}$ injured mice, without differences between the two genotypes (17.2 \pm 1.6 vs $18.6 \pm 1.0 \mathrm{~mm}^{3} \pm$ SEM Fig. $3 \mathrm{a}-\mathrm{c}$ ). We then assessed the neuronal density in a cortical region traced at a distance of $350 \mu \mathrm{m}$ from the contusion edge (Fig. 3d, e) and in the corresponding contralateral hemisphere. MASP$2^{-l-}$ mice had higher neuronal density than WT mice at 6 weeks after TBI $(31.5 \%, p<0.05$, Fig. $3 \mathrm{~g})$, indicating that the absence of MASP-2 functional activity was significantly protective against neuronal death after TBI.

\section{MASP-2 ${ }^{-/-}$mice did not show different astrogliosis and microglial activation after TBI}

At 6 weeks after TBI, we measured astrogliosis and microglial activation quantifying the GFAP and CD11b immunopositive area at the edge of the contusion area. WT and MASP-2 ${ }^{-1-}$ injured mice showed comparable astrogliosis $(17.8 \pm 2.1$ vs $16.5 \pm 2.3$ staining \% area \pm SEM) and microglial activation ( $8.5 \pm 1.8$ vs $8.7 \pm 1.7$ staining $\%$ area $\pm S E M)$ when assessed as the total stained area (Fig. 4a, b). Since microglia morphology is indicative of the state of microglial activation, we subsequently analysed microglial cell shape descriptors 
Table 1 Summary table

\begin{tabular}{|c|c|c|c|c|c|c|c|c|}
\hline \multirow[t]{2}{*}{ Strain } & \multicolumn{2}{|l|}{1 week } & \multicolumn{2}{|l|}{2 week } & \multicolumn{2}{|l|}{3 week } & \multicolumn{2}{|l|}{4 week } \\
\hline & $\%$ of WT & $p$ value & $\%$ of WT & $p$ value & $\%$ of WT & $p$ value & $\%$ of WT & $p$ value \\
\hline \multicolumn{9}{|l|}{ MASP-2 $2^{-/-}$} \\
\hline Neuroscore & +11.4 & 0.6079 & +4.3 & 0.9605 & +13.6 & 0.4541 & -5.9 & 0.8809 \\
\hline $\begin{array}{l}\text { Beam Walk } \\
\mathrm{MBL}^{-/-}\end{array}$ & +5.5 & 0.9608 & +27.9 & 0.0681 & +32.1 & 0.0202 & +36 & 0.0091 \\
\hline Neuroscore & +33.7 & 0.0997 & +42.8 & 0.0023 & +37.2 & 0.0011 & +35.6 & 0.0003 \\
\hline $\begin{array}{l}\text { Beam Walk } \\
\text { FCN-A }{ }^{-/-}\end{array}$ & +12.9 & 0.2972 & +24.03 & 0.0131 & +25.1 & 0.0133 & +21.4 & 0.0742 \\
\hline Neuroscore & +19.7 & 0.9253 & +0.37 & $>0.9999$ & -7.9 & 0.7784 & +5.3 & 0.9171 \\
\hline $\begin{array}{l}\text { Beam Walk } \\
\text { CL-11 }\end{array}$ & +6.7 & 0.9253 & +15 & 0.5412 & +13 & 0.685 & +9.9 & 0.829 \\
\hline Neuroscore & +16 & 0.4086 & +13.5 & 0.5552 & +11.2 & 0.631 & +11.9 & 0.5552 \\
\hline $\begin{array}{l}\text { Beam Walk } \\
\text { MBL-C }^{-/-}\end{array}$ & -4.9 & 0.8735 & +11.1 & 0.3198 & +15.8 & 0.0711 & +23.5 & 0.0024 \\
\hline Neuroscore & +10 & $>0.9999$ & +2.9 & $>0.9999$ & +11.1 & $>0.9999$ & -16.7 & 0.8796 \\
\hline $\begin{array}{l}\text { Beam Walk } \\
\text { MASP-1/3-1- }\end{array}$ & -3.5 & $>0.9999$ & -3.5 & $>0.9999$ & 3.6 & $>0.9999$ & +3.9 & $>0.9999$ \\
\hline Neuroscore & +9.1 & 0.9426 & +11.9 & 0.784 & +8.7 & 0.8759 & -1.9 & 0.9976 \\
\hline 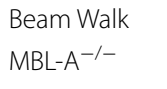 & +1.07 & 0.9997 & +0.56 & $>0.9999$ & -2.6 & 0.997 & 0 & $>0.9999$ \\
\hline Neuroscore & +4.5 & 0.9986 & +7.1 & 0.989 & -2.9 & 0.9986 & -19.5 & 0.589 \\
\hline Beam Walk & -10 & 0.9025 & -4.2 & 0.9932 & -9.8 & 0.9133 & -11.01 & 0.8786 \\
\hline
\end{tabular}

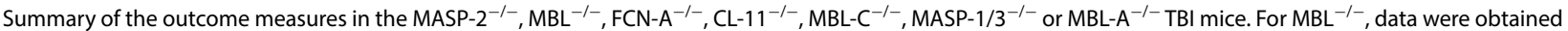
from the previous paper by Longhi et al. [32]

[21]. Our analysis revealed that the proinflammatory morphology of microglia persists for as long as 6 weeks after TBI. Increased size (area, perimeter and Feret diameter) and higher ramified morphology (lower circularity) were observed in the ipsilateral region compared to the contralateral hemisphere $(p<0.01)$. However, no differences in microglial morphology were observed when comparing WT and MASP- $2^{-/-}$mice (Fig. 4c, d).

\section{MASP $-2^{-/-}$mice had impaired Lectin Pathway activation and normal MBL-C deposition}

Since MBL-C deposition can be detected in the brain after TBI [32], we measured the relative amount of MBL-C deposits in WT and MASP-2 ${ }^{-1-}$ injured mice 30 min (') after injury (Fig. 5a). We observed an increased deposition of MBL-C in TBI mice (compared to sham), regardless of the genotype (WT vs $\mathrm{MASP}^{-1-}{ }^{-1} 1.30$ $( \pm 0.08) \times 10^{11}$ vs $1.10( \pm 0.12) \times 10^{11}$ fluorescence integrated density \pm SEM Fig. $5 \mathrm{~b}$ ) indicating that the absence of MASP-2 did not affect the deposition of MBL-C. We then tested LP functional activity in mouse plasma using a functional in vitro assay [37] on mannan-coated plates, which measures LP activation through MBL $(92.6 \pm 15.2$ vs $7.3 \pm 1.7$ optical density \pm SEM) [38]. The absence of
C4b deposition shows that MBL driven LP activation does not occur in MASP- $2^{-/-}$TBI mice, indicating that not even residual activation of the LP is occurring in MASP- $2^{-/-}$mice following TBI (Fig. 5c).

\section{Discussion}

This study compares the long-term outcome after experimental TBI in mouse lines with targeted deficiencies of the LP-specific components, namely the recognition molecules ficolin-A, CL-11, MBL-C and MBL-A (both individually and combined) and the serine-proteases MASP-2, MASP-1 and MASP-3. To obtain a comparative outcome analysis, we developed a health score based on the neuroscore and beam walk test, two behavioural analyses evaluating sensorimotor deficits, over 4 weeks of observation. We found that MASP- $2^{-1-}, \mathrm{MBL}^{-1-}$ and $\mathrm{FCN}_{-} \mathrm{A}^{-1-}$ mice had lower neurological deficits after TBI, indicating that these LP components are actively involved in driving the traumatic lesion and identifies them as possible pharmacological targets to reduce post-traumatic loss of functional activity and to improve recovery and clinical outcome. 


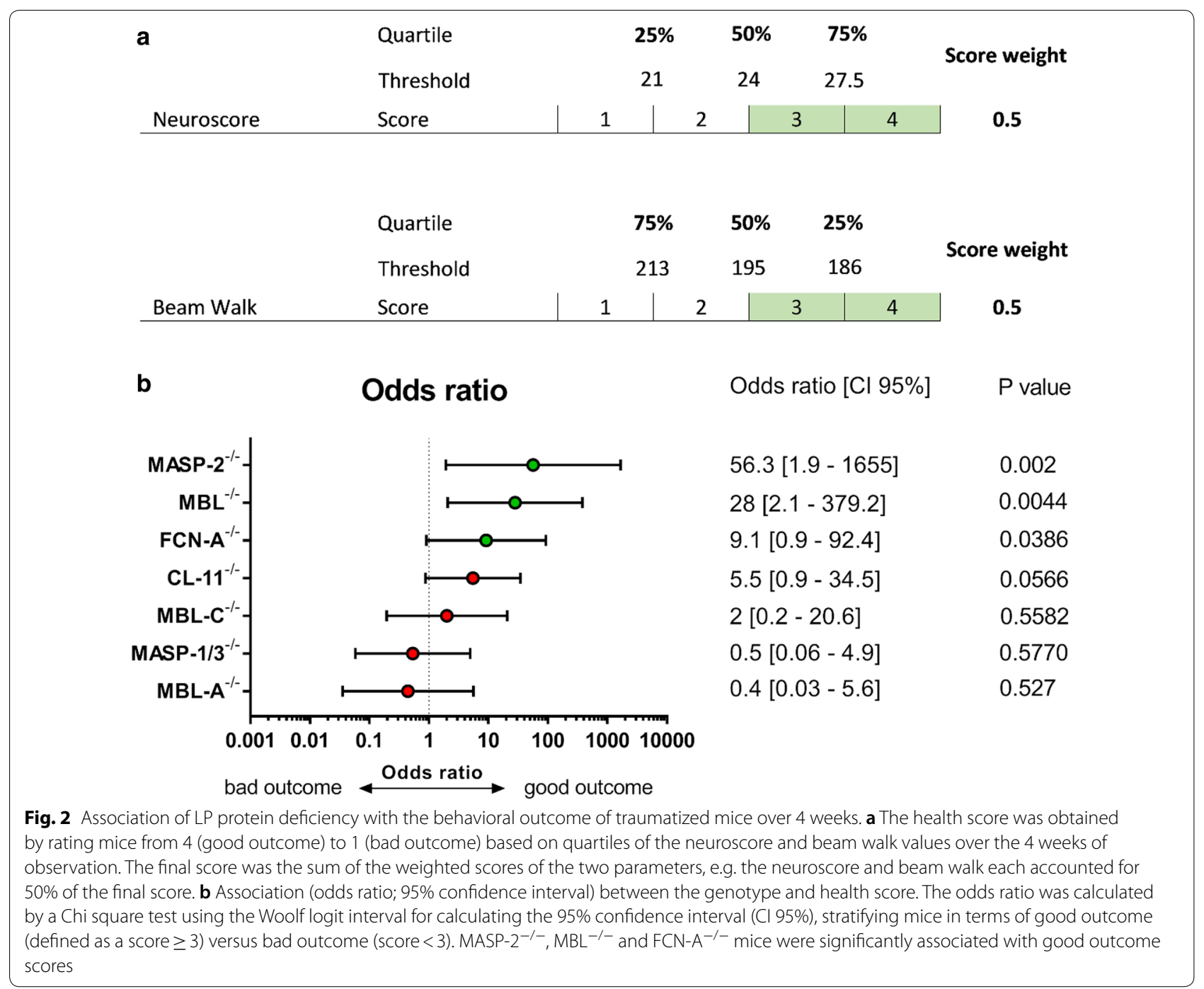

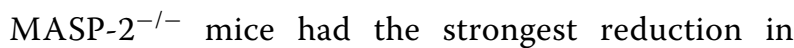
sensorimotor deficits after TBI, which is in line with the key role of this enzyme in driving LP dependent complement activation. Of note, 6 weeks after injury, MASP-2 ${ }^{-/-}$TBI mice had higher neuronal density in the ipsilateral cortex compared to WT TBI mice, an important result given the severity of the TBI model used which has a major impact on neuronal viability and leads to major brain tissue loss. This is similar to what is observed in patients suffering from severe injury [23].

Our data underline the importance of the LP in TBI pathophysiology and identify MASP-2 as a key enzyme. Interestingly, neither of the other LP-associated enzymes, i.e. MASP-1 or MASP-3 appear to be involved in the posttraumatic loss of CNS functions following TBI, since MASP $-1 / 3^{-/-}$mice suffered from a similar degree of sensorimotor deficits than their WT controls. While it is accepted that only MASP-2 can generate the $\mathrm{C} 3$ convertase of the LP $(\mathrm{C} 4 \mathrm{bC} 2 \mathrm{a})$ through its ability to cleave both C4 and C2 [39, 40], MASP-1 can support MASP-2 functional activity by cleaving $\mathrm{C} 2$ and enhance the conversion of zymogen MASP-2 into its enzymatically active form [41, 42].

It has been postulated that MASP-1 is an essential activator of MASP-2 [43] based on in vitro experiments using MASP-1/3 or MASP-1 deficient sera or sera treated with MASP-1 specific inhibitors. However, in in vivo models of MASP-2 dependent pathophysiology, such as ischemia reperfusion injury and TBI (reported here), the requirement for MASP-1 to activate MASP-2 appears to be negligible, since the absence of MASP-1 (or MASP-3) does not protect from MASP-2 dependent tissue injury. MASP-1 facilitates the conversion of zymogen MASP-2 into its enzymatically active form, most likely because 


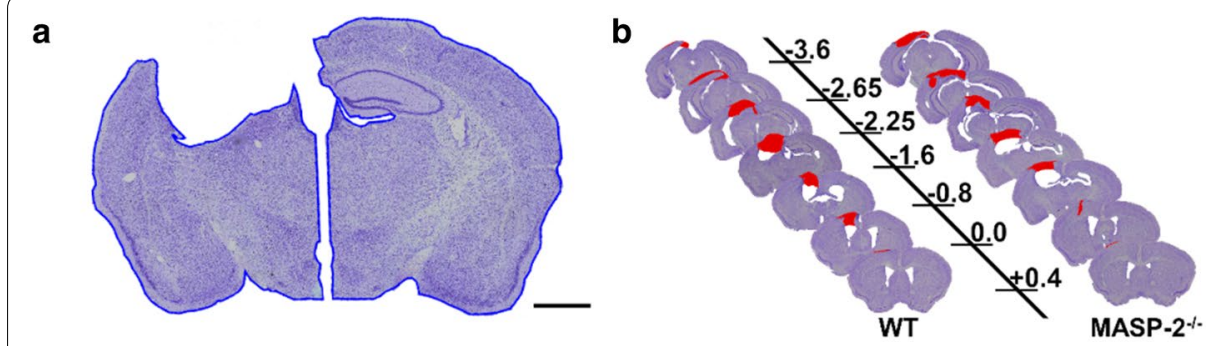

d

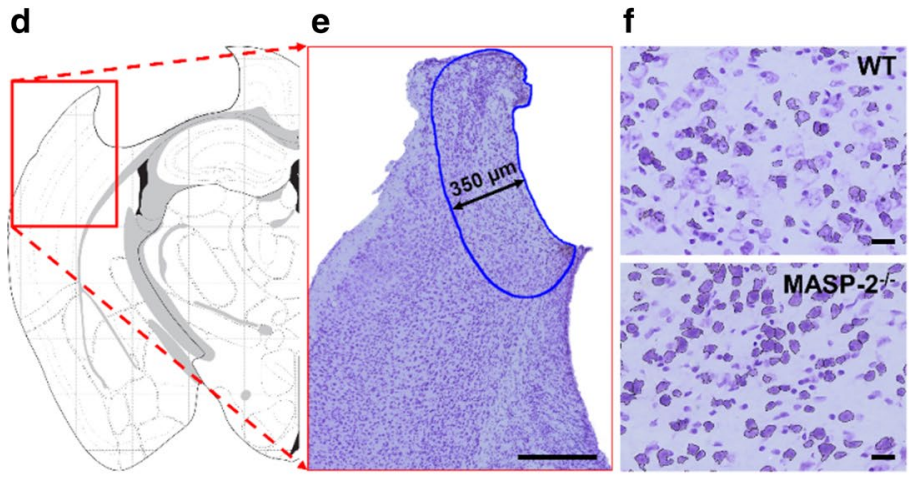

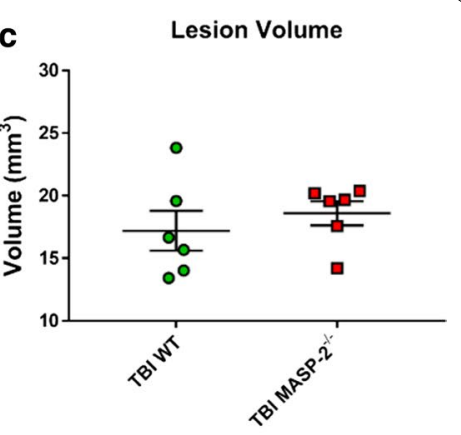

g Contra
Ipsi

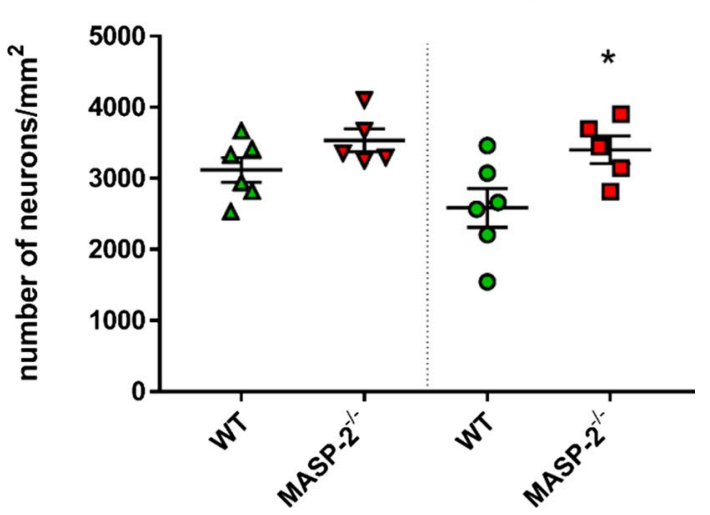

Fig. 3 Histological analysis of lesion at 6 weeks after TBI in WT and MASP- $2^{-/}$mice. a Representative image of Cresyl violet staining in ipsilateral and contralateral hemisphere. The lesion volume was evaluated based on the different extents of the ipsilateral and contralateral hemispheres, outlined in blue. Scale bar $1 \mathrm{~mm}$. b Representative images of quantified sections for lesion volume at 6 weeks after TBI in WT and MASP-2 $2^{-/-}$mice. Distance from bregma in $\mathrm{mm}$ is indicated. c Quantification of the lesion showed no differences between WT and MASP- $2^{-1-}$ mice 6 weeks after TBI. The data is shown as a scatter dot plot, line at mean \pm SEM $(n=6)$; Mann-Whitney test. $\mathbf{d}$ Anatomical location of area of interest (red box). $\mathbf{e}$ Positioning of the cortical region of interest (blue outline) for calculating neuronal cell viability, traced at a distance of $350 \mu \mathrm{m}$ from the contusion edge. Scale bar $350 \mu \mathrm{m}$. f $20 \times$ high magnified fields of view showing a higher presence of neurons in MASP- $2^{-1-}$ than WT mice. Scale bars $20 \mu \mathrm{m}$. g Quantification of neuronal density in the region of interest. MASP-2 ${ }^{-/}$mice had higher neuronal density in the ipsilateral cortex than WT mice. The data is shown as a scatter dot plot, line at mean \pm SEM $(n=5-6)$; Two-way Anova followed by Sidak's post hoc test, ${ }^{*} p<0.05$ compared with ipsi WT

the relatively low abundance of MASP-2 compared to MASP-1 limits LP-specific trans-activation events [44, 45]. In an experimental model of ischemic stroke, we reported that combined deficiency of MASP-1 and MASP-3 did not affect the ischemic outcome, while that of MASP-2 was protective [18]. Therefore, we hypothesized that ischemic brain injury involved a MASP-2 dependent pathophysiological process, thus underlining that MASP-1 is not an essential activator of MASP-2. Consistent with this conclusion is our present observation that the total absence of LP-mediated complement activation in MASP- $2^{-1-}$ mice is protecting from posttraumatic injury, while MASP- $1 / 3$ double deficient mice show no degree of protection. In this context, it is important to keep in mind that MASP-2 can also cleave C3 directly through a $\mathrm{C} 4$ and $\mathrm{C} 2$ independent bypass activation of native C3 [46].
Our study shows that $\mathrm{MBL}^{-1-}$ and $\mathrm{FCN}-\mathrm{A}^{-1-}$ mice were significantly associated with a good outcome score indicating that they may be the relevant initiator molecules. In line with this, we have previously shown the effectiveness of targeting MBL in TBI mice by inhibiting MBL with Polyman9, a polymannosylated compound, which binds to the carbohydrate recognition domain of MBL, attenuating sensorimotor deficits up to 4 weeks after TBI [28, 32]. As for ficolin-A, the mouse orthologue of human ficolin-2, no data are available on its role in the context of brain injury. In TBI patients ficolin-2 has been found in the peri-contusional brain area at significantly higher levels than in the brain from control patients [23]. Its role in TBI has to be further investigated.

A common feature of the initiators of the lectin complement pathway is their ability to interact with MASP-2 to trigger the activation of the LP. Thus, 


\section{(See figure on next page.)}

Fig. 4 Inflammation markers and microglia shape descriptors 6 weeks after TBI in WT and MASP-2 ${ }^{-1-}$ mice. a, b MASP-2 deletion did not affect the level of inflammatory markers such as glial fibrillary acidic protein (GFAP) and CD1 1b. The data is shown as a scatter dot plot, line at mean \pm SEM $(n=5-6)$; unpaired $t$ test. $\mathbf{c}$ Shape descriptors of CD11 b positive cells showed that at 6 weeks after TBI microglia are still activated, having increased area, perimeter, Feret diameter and ramifications (indicated by lower circularity) higher in ipsi than in contralateral side. The drawings beside the $y$-axis indicate the expected values for each parameter depending on cell shape or symmetry. Microglia morphology did not differ between the two genotypes. The data is shown as a scatter dot plot, line at mean \pm SEM $(n=6)$; Two-way Anova followed by Sidak's post hoc test. $\mathbf{d}$ Representative high-magnification images of CD11b positive cells showing activated microglia in the ipsilateral side of both WT and MASP-2 ${ }^{-/-}$TBI mice, scale bar $20 \mu \mathrm{m}$

MASP-2 should be a more effective target than one of the five LP initiators. The data obtained in this work supports this notion, as MASP-2 deficiency provides better protection against TBI damage than that of a specific initiator. However, as previously reported in models of ischemia/reperfusion injury, recognition molecules can have detrimental effects independently from the LP cascade activation [16, 47]. In particular, MBL itself has been shown to promote vascular injury on endothelial cells having undergone hypoxic stimulus by direct action-including structural damage to the endothelial cell cytoskeleton-without requiring LP activation [16]. Consistent with this finding, genetic deletion of MBL or its pharmacological inhibition were sufficient to obtain significant protection in experimental models of ischemic stroke, where vascular dysfunction is critical $[17,20,48]$. The fact that in experimental TBI, MBL depletion provided a lower degree of protection than MASP-2 depletion may suggest that the complement-independent vascular effects of MBL are less important for TBI pathophysiology. In line with this suggestion, the presence of MBL within the TBI-injured area was not different in WT and MASP- $2^{-1-}$ mice, supporting the hypothesis that LP-independent detrimental effects of MBL have a limited contribution to TBI sequelae. Moreover, most of the MBL in the lesion core area was extravascular, implying that MBL-driven vascular effects may be marginal, at variance with what happens in ischemic injury.

Microglia activation may contribute to specific behavioural deficits, like sickness behaviour in mice, corresponding to depressive behaviours seen in TBI patients, months after injury [49, 50]. Here we report that 6 weeks after TBI, microglia are still activated, showing increased size and ramifications in ipsi- compared to contra-lateral side, with no difference between WT and MASP-2 $2^{-/-}$mice. We previously found that early $(48 \mathrm{~h})$ after ischemia/reperfusion injury MASP-2 deletion was associated with microglia presenting typical anti-inflammatory morphological features, as opposed to the hypertrophic microglial morphology associated with the phagocytic activity and pro-inflammatory state present in ischemic WT brains [18]. We cannot exclude that
MASP-2 deletion affected microglia activation at earlier time points after TBI, with consequences on the overall outcome. However, data show that this effect is no more detectable at chronic time points.

It is known that the complement system drives microglia-driven synaptic control in memory loss [51] and in chronic neurodegenerative disease like Alzheimer's [52], a possible long-term consequence of TBI [53]. However complement-mediated synapse elimination appears to be associated with proteins of the classical pathway, particularly C1q, released locally in the brain [52, 54], with no specific involvement of the LP, as shown here.

The results presented here, obtained in experimental TBI, pointing to MASP-2 as a key enzyme in TBI pathology, are in line with what is observed in TBI patients. Namely, we previously reported that: (1) the complement system is fully activated down to the level of the formation of the terminal complement complex; (2) the lectin pathway components are persistently present, up to 5 days post-TBI; and (3) MASP-2 in the brain is significantly increased and associated with TBI severity, indicated by abnormal pupil reactivity and traumatic subarachnoid haemorrhage [23]. Moreover others reported that increased circulating levels of MASP-2 are associated with a poor outcome at 90 days after injury [55].

It should not be excluded that other pathways of complement system may have a role in propagating chronic post-TBI pathology. Indeed, we also reported an increased presence of MASP-3 in the brains of TBI patients compared to control patients [23], supporting a role of the alternative pathway in TBI. Indeed pharmacological inhibition of the alternative pathway provided significant improvements in histological, and functional recovery in an experimental model of TBI [56].

\section{Conclusion}

This study highlights the significant contribution of LP to the post-traumatic inflammatory pathology following TBI and shows that the highest degree of protection is achieved through the absence of the LP key enzyme MASP-2, underlying the therapeutic utility of MASP-2 targeting following acute brain injury. This points to LP 

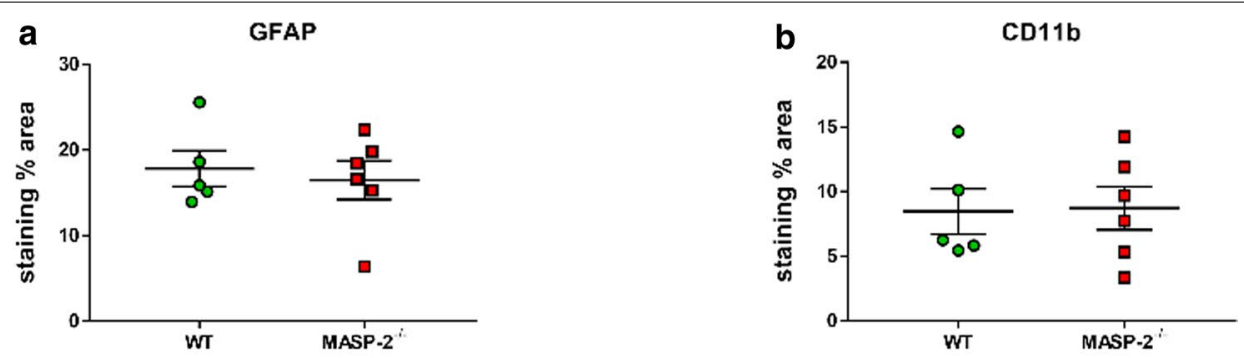

C
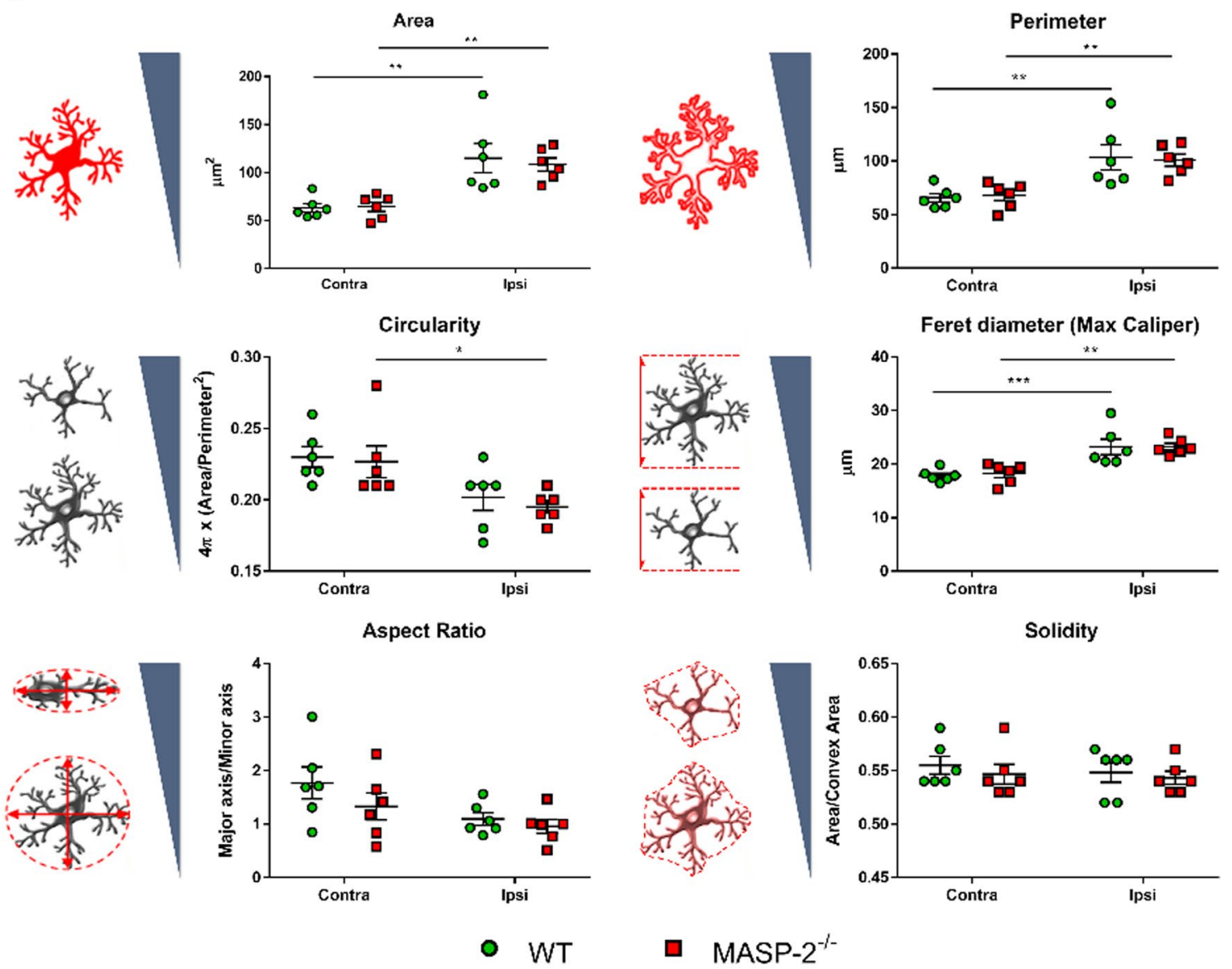

a $\mathrm{MASP}_{-} 2^{-/-}$

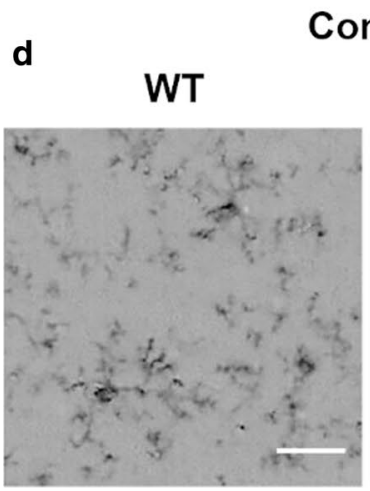

Contra
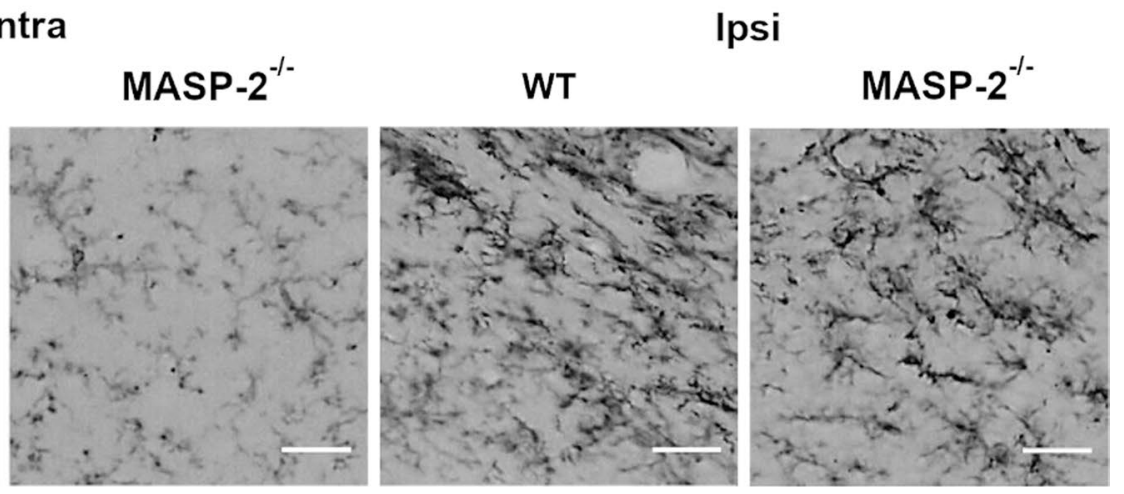
a
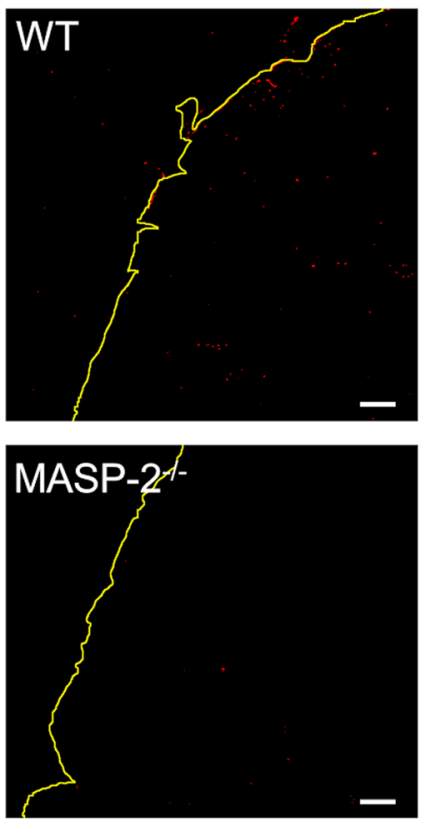

TBI
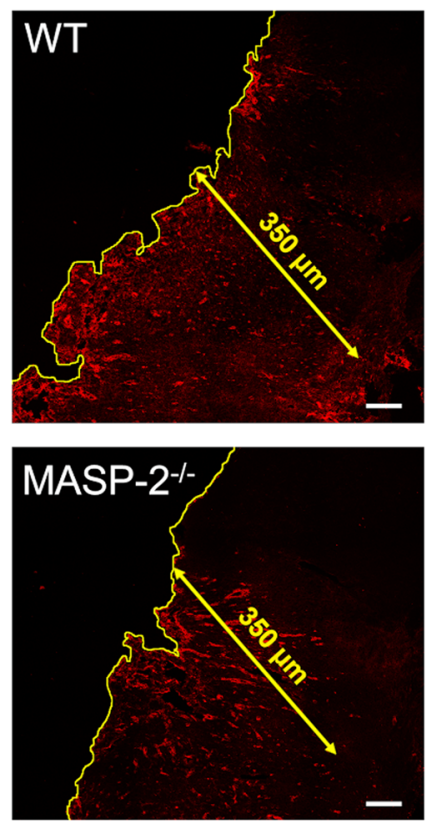

b

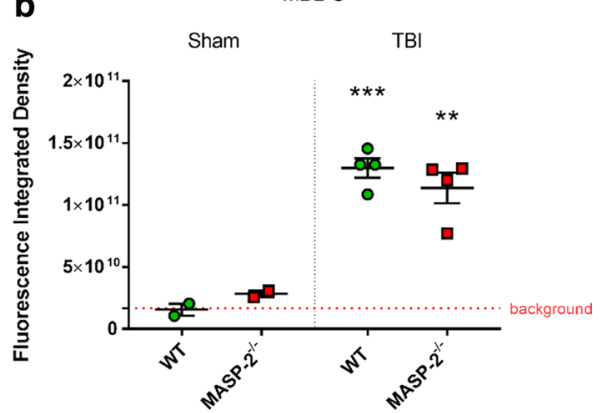

C

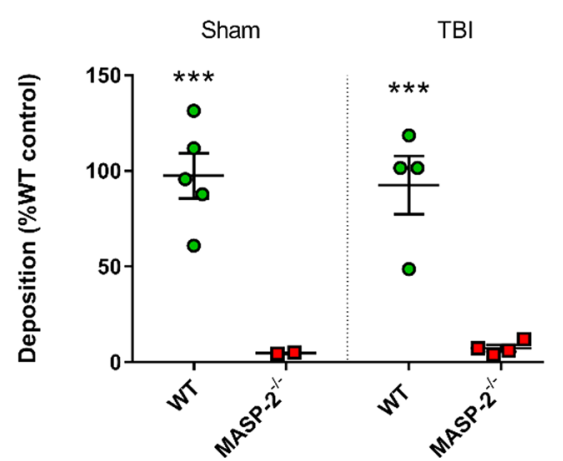

Fig. 5 Brain MBL-C deposition and plasmatic LP activation 30' after TBI in WT or MASP- $2^{-/-}$mice. a Representative low-magnification images of MBL-C immunolabeling at $30^{\prime}$ after TBI or sham surgery (the cortical edge is outlined in yellow). MBL-C quantification was done over an area of $350 \mu \mathrm{m}$ from the contusion edge (Fig. 2). Scale bars $50 \mu \mathrm{m}$. b MBL-C deposition in brains of MASP-2 ${ }^{-/}$mice was similar to that of WT. Data is shown as a scatter dot plot, line at mean \pm SEM $(n=2-4)$. Two-way Anova followed by Sidak's post hoc test, ${ }^{* *} p<0.01$ compared with Sham MASP-2 ${ }^{-/-}$, ${ }^{* * *} p<0.001$ compared with Sham WT. $\mathbf{c}$ In vitro assay for MBL-driven LP activation on mannan — plasma from MASP- $2^{-/-}$lack C4 convertase activity, resulting in minimal C4b deposition compared to WT mice. The data is shown as a scatter dot plot, line at mean \pm SEM ( $n=2-4)$, Two-way Anova followed by Sidak's post hoc test, ${ }^{* * *} p<0.001$ compared with Sham or TBI WT

and MASP-2 as novel pharmacological targets for TBI, thus paving the way for future development of clinical strategies. MASP-2 represents a unique target: it is a single, low-abundance enzyme that is exclusively synthesized in the liver [57], so the effectiveness of systemic MASP-2 inhibitory agents is not complicated by local biosynthesis in the brain and the limitations imposed by the blood-brain barrier. Of note, an inhibitory antibody against MASP-2 (Narsoplimab) is currently undergoing phase 3 clinical trials for the treatment of Hematopoietic Stem Cell Transplant-Associated TMA (ClinicalTrials.gov Identifier: NCT04247906), IgA Nephropathy (NCT03608033) and Atypical Hemolytic Uremic Syndrome (NCT03205995) and in a phase 2 clinical trial for the treatment of Lupus Nephritis (NCT02682407), thus making the present work potentially transferable to the clinical setting in the near future.

\section{Abbreviations}

LP: Lectin pathway; WT: Wild-type; TBI: Traumatic brain injury; BBB: Blood-brain barrier; DAMPs: Damage-associated molecular patterns.

\section{Acknowledgements}

Not applicable.

\section{Authors' contributions}

DM conducted the experiments, acquired and analyzed the data, drafted the $\mathrm{ms} ; \mathrm{MO}, \mathrm{DM}, \mathrm{Sl}, \mathrm{CP}$ conducted the experiments, acquired and analyzed the data; SF contributed to experimental design, analyzed the data and provided critical discussion of the ms; NJL, SR and RW provided the knock out mice, conducted the histological analysis and analyzed the data; WJS provided critical review of the ms and expertise on the lectin pathway; MGDS conceived and designed the study, supervised the study, analyzed the data, wrote the ms.

\section{Funding}

$\mathrm{DM}, \mathrm{MO}, \mathrm{SF}, \mathrm{NJL}, \mathrm{DM}, \mathrm{CP}, \mathrm{SI}$ and MGDS received grant support from ERA-NETNEURON, JTC 2016 and Italian Ministry of Health (Ministero della Salute): LEAP (grant number: NEURON9-FP-044). SR and RW received grant support from ERA-NET-NEURON, JTC 2016 and Medical Research Council (MRC), and from Grant MR/R002983/1, MRC.

\section{Availability of data and material}

The data sets generated and/or analyzed during the current study are available in the Figshare repository, https://doi.org/10.6084/m9.figshare.12416597.

\section{Ethics approval and consent to participate}

Procedures involving animals and their care were conducted in conformity with institutional guidelines in compliance with national and international laws and policies (prot.9F5F5.81 authorisation n 753/2017-PR). 


\section{Consent for publication \\ Not applicable.}

\section{Competing interests}

WJS is a shareholder of Omeros Corp. The remaining authors declared no potential conflicts of interest with respect to the research, authorship, and/or publication of this article.

\begin{abstract}
Author details
${ }^{1}$ Department of Neuroscience, Istituto di Ricerche Farmacologiche Mario Negri IRCCS, via Mario Negri 2, 20156 Milan, Italy. ${ }^{2}$ Department of Respiratory Sciences, University of Leicester, University Road, LE1 9HN Leicester, UK. ${ }^{3}$ Department of Veterinary Medicine, University of Cambridge, Madingley Road, CB3 OES Cambridge, UK. ${ }^{4}$ Present Address: San Raffaele Scientific Institute, San Raffaele Hospital, 20132 Milan, Italy. ${ }^{5}$ Present Address: National Research Council (CNR), Institute of Neuroscience, 20129 Milan, Italy.
\end{abstract}

Received: 22 July 2020 Accepted: 24 September 2020 Published online: 28 October 2020

\section{References}

1. Greig NH, Tweedie D, Rachmany L, Li Y, Rubovitch V, Schreiber S et al (2014) Incretin mimetics as pharmacologic tools to elucidate and as a new drug strategy to treat traumatic brain injury. Alzheimers Dement 10:S62-S75

2. LaPlaca MC, Simon CM, Prado GR, Cullen DK (2007) CNS injury biomechanics and experimental models. Prog Brain Res 161:13-26

3. Cheng G, Kong R, Zhang L, Zhang J (2012) Mitochondria in traumatic brain injury and mitochondrial-targeted multipotential therapeutic strategies. Br J Pharmacol 167:699-719

4. Mclntosh TK, Juhler M, Wieloch T (1998) Novel pharmacologic strategies in the treatment of experimental traumatic brain injury. J Neurotrauma 15:731-769

5. Simon DW, McGeachy MJ, Bayır H, Clark RSB, Loane DJ, Kochanek PM (2017) The far-reaching scope of neuroinflammation after traumatic brain injury. Nat Rev Neurol 13:171-191

6. Temkin NR, Anderson GD, Winn HR, Ellenbogen RG, Britz GW, Schuster J et al (2007) Magnesium sulfate for neuroprotection after traumatic brain injury: a randomised controlled trial. Lancet Neurol 6:29-38

7. Bains M, Hall ED (2012) Antioxidant therapies in traumatic brain and spinal cord injury. Biochim Biophys Acta BBA Mol Basis Dis 1822:675-684

8. Das M, Royer TV, Leff LG (2012) Interactions between aquatic bacteria and an aquatic hyphomycete on decomposing maple leaves. Fungal Ecol $5: 236-244$

9. Maas Al, Stocchetti N, Bullock R (2008) Moderate and severe traumatic brain injury in adults. Lancet Neurol 7:728-741

10. Bellander B-M, Singhrao SK, Ohlsson M, Mattsson P, Svensson M (2001) Complement activation in the human brain after traumatic head injury. J Neurotrauma 18:1295-1311

11. Stahel PF, Morganti-Kossmann MC, Perez D, Redaelli C, Gloor B, Trentz O et al (2001) Intrathecal levels of complement-derived soluble membrane attack complex (sC5b-9) correlate with blood-brain barrier dysfunction in patients with traumatic brain injury. J Neurotrauma 18:773-781

12. Leinhase I, Schmidt OI, Thurman JM, Hossini AM, Rozanski M, Taha ME et al (2006) Pharmacological complement inhibition at the C3 convertase level promotes neuronal survival, neuroprotective intracerebral gene expression, and neurological outcome after traumatic brain injury. Exp Neurol 199:454-464

13. Stahel PF, Flierl MA, Morgan BP, Persigehl I, Stoll C, Conrad C et al (2009) Absence of the complement regulatory molecule CD59a leads to exacerbated neuropathology after traumatic brain injury in mice. J Neuroinflamm 6:2

14. Burk A-M, Martin M, Flierl MA, Rittirsch D, Helm M, Lampl L et al (2012) Early complementopathy after multiple injuries in humans. Shock 37:348-354

15. Orsini F, De Blasio D, Zangari R, Zanier ER, De Simoni M-G (2014) Versatility of the complement system in neuroinflammation, neurodegeneration and brain homeostasis. Front Cell Neurosci 8:380
16. Neglia L, Fumagalli S, Orsini F, Zanetti A, Perego C, De Simoni M-G (2020) Mannose-binding lectin has a direct deleterious effect on ischemic brain microvascular endothelial cells. J Cereb Blood Flow Metab 40:1608-1620

17. Orsini F, Villa P, Parrella S, Zangari R, Zanier ER, Gesuete R et al (2012) Targeting mannose-binding lectin confers long-lasting protection with a surprisingly wide therapeutic window in cerebral ischemia. Circulation 126:1484-1494

18. Orsini F, Chrysanthou E, Dudler T, Cummings WJ, Takahashi M, Fujita Tet al (2016) Mannan binding lectin-associated serine protease-2 (MASP-2) critically contributes to post-ischemic brain injury independent of MASP-1. J Neuroinflamm 13:213

19. Neglia L, Oggioni M, Mercurio D, De Simoni M-G, Fumagalli S (2020) Specific contribution of mannose-binding lectin murine isoforms to brain ischemia/reperfusion injury. Cell Mol Immunol 17:218-226

20. Orsini F, Fumagalli S, Császár E, Tóth K, De Blasio D, Zangari R et al (2018) Mannose-binding lectin drives platelet inflammatory phenotype and vascular damage after cerebral ischemia in mice via IL (interleukin)-1a. Arterioscler Thromb Vasc Biol 38:2678-2690

21. Zanier ER, Fumagalli S, Perego C, Pischiutta F, De Simoni M-G (2015) Shape descriptors of the "never resting" microglia in three different acute brain injury models in mice. Intensive Care Med Exp 3:7

22. Longhi L, Perego C, Ortolano F, Zanier ER, Bianchi P, Stocchetti N et al (2009) C1-inhibitor attenuates neurobehavioral deficits and reduces contusion volume after controlled cortical impact brain injury in mice* Crit Care Med 37:659-665

23. De Blasio D, Fumagalli S, Orsini F, Neglia L, Perego C, Ortolano F et al (2019) Human brain trauma severity is associated with lectin complement pathway activation. J Cereb Blood Flow Metab 39:794-807

24. Pischiutta F, D'Amico G, Dander E, Biondi A, Biagi E, Citerio G et al (2014) Immunosuppression does not affect human bone marrow mesenchymal stromal cell efficacy after transplantation in traumatized mice brain. Neuropharmacology 79:119-126

25. Zanier ER, Montinaro M, Vigano M, Villa P, Fumagalli S, Pischiutta F et al (2011) Human umbilical cord blood mesenchymal stem cells protect mice brain after trauma. Crit Care Med 39:2501-2510

26. Zanier ER, Marchesi F, Ortolano F, Perego C, Arabian M, Zoerle T et al (2015) Fractalkine receptor deficiency is associated with early protection but late worsening of outcome following brain trauma in mice. J Neurotrauma 33:1060-1072

27. Zanier ER, Pischiutta F, Riganti L, Marchesi F, Turola E, Fumagalli S et al (2014) Bone marrow mesenchymal stromal cells drive protective M2 microglia polarization after brain trauma. Neurotherapeutics 11:679-695

28. De Blasio D, Fumagalli S, Longhi L, Orsini F, Palmioli A, Stravalaci M et al (2017) Pharmacological inhibition of mannose-binding lectin ameliorates neurobehavioral dysfunction following experimental traumatic brain injury. J Cereb Blood Flow Metab 37:938-950

29. Brody DL, Mac Donald C, Kessens CC, Yuede C, Parsadanian M, Spinner M et al (2007) Electromagnetic controlled cortical impact device for precise, graded experimental traumatic brain injury. J Neurotrauma 24:657-673

30. Fujimoto ST, Longhi L, Saatman KE, Conte V, Stocchetti N, Mclntosh TK (2004) Motor and cognitive function evaluation following experimental traumatic brain injury. Neurosci Biobehav Rev 28:365-378

31. Mouzon BC, Bachmeier C, Ferro A, Ojo J-O, Crynen G, Acker CM et al (2014) Chronic neuropathological and neurobehavioral changes in a repetitive mild traumatic brain injury model. Ann Neurol 75:241-254

32. Longhi L, Orsini F, De Blasio D, Fumagalli S, Ortolano F, Locatelli $M$ et al (2014) Mannose-binding lectin is expressed after clinical and experimental traumatic brain injury and its deletion is protective*. Read Online Crit Care Med Soc Crit Care Med 42:1910-1918

33. Perego C, Fumagalli S, De Simoni M-G (2011) Temporal pattern of expression and colocalization of microglia/macrophage phenotype markers following brain ischemic injury in mice. J Neuroinflamm 8:174

34. Fumagalli S, Fiordaliso F, Perego C, Corbelli A, Mariani A, De Paola M et al (2019) The phagocytic state of brain myeloid cells after ischemia revealed by superresolution structured illumination microscopy. J Neuroinflamm $16: 9$

35. Petersen SV, Thiel S, Jensen L, Steffensen R, Jensenius JC (2001) An assay for the mannan-binding lectin pathway of complement activation. J Immunol Methods 257:107-116 
36. Dodds AW (1993) Small-scale preparation of complement components C3 and C4. Methods Enzymol 223:46-61

37. Schwaeble WJ, Lynch NJ, Clark JE, Marber M, Samani NJ, Ali YM et al (2011) Targeting of mannan-binding lectin-associated serine protease-2 confers protection from myocardial and gastrointestinal ischemia/reperfusion injury. Proc Natl Acad Sci 108:7523-7528

38. Ali YM, Lynch NJ, Haleem KS, Fujita T, Endo Y, Hansen S et al (2012) The lectin pathway of complement activation is a critical component of the innate immune response to pneumococcal infection. PLoS Pathog 8:e1002793

39. Vang Petersen S, Thiel S, Jensenius JC (2001) The mannan-binding lectin pathway of complement activation: biology and disease association. Mol Immunol 38:133-149

40. Wallis R, Mitchell DA, Schmid R, Schwaeble WJ, Keeble AH (2010) Paths reunited: initiation of the classical and lectin pathways of complement activation. Immunobiology 215:1-11

41. Chen C-B, Wallis R (2004) Two mechanisms for mannose-binding protein modulation of the activity of its associated serine proteases. J Biol Chem 279:26058-26065

42. Héja D, Harmat V, Fodor K, Wilmanns M, Dobó J, Kékesi KA et al (2012) Monospecific inhibitors show that both mannan-binding lectinassociated serine protease-1 (MASP-1) and -2 are essential for lectin pathway activation and reveal structural plasticity of MASP-2. J Biol Chem 287:20290-20300

43. Héja D, Kocsis A, Dobó J, Szilágyi K, Szász R, Závodszky P et al (2012) Revised mechanism of complement lectin-pathway activation revealing the role of serine protease MASP-1 as the exclusive activator of MASP-2. Proc Natl Acad Sci 109:10498-10503

44. Kocsis A, Kékesi KA, Szász R, Végh BM, Balczer J, Dobó J et al (2010) Selective inhibition of the lectin pathway of complement with phage display selected peptides against mannose-binding lectin-associated serine protease (MASP)-1 and -2: significant contribution of MASP-1 to lectin pathway activation. J Immunol 185:4169-4178

45. Degn SE, Kjaer TR, Kidmose RT, Jensen L, Hansen AG, Tekin M et al (2014) Complement activation by ligand-driven juxtaposition of discrete pattern recognition complexes. Proc Natl Acad Sci 111:13445-13450

46. Yaseen S, Demopulos G, Dudler T, Yabuki M, Wood CL, Cummings WJ et al (2017) Lectin pathway effector enzyme mannan-binding lectin-associated serine protease- 2 can activate native complement $C 3$ in absence of C4 and/or C2. FASEB J 31:2210-2219
47. van der Pol P, Schlagwein N, van Gijlswijk DJ, Berger SP, Roos A, Bajema IM et al (2012) Mannan-binding lectin mediates renal ischemia/reperfusion injury independent of complement activation. Am J Transplant 12:877-887

48. Gesuete R, Storini C, Fantin A, Stravalaci M, Zanier ER, Orsini F et al (2009) Recombinant C1 inhibitor in brain ischemic injury. Ann Neurol 66:332-342

49. Dantzer R (2001) Cytokine-induced sickness behavior: where do we stand? Brain Behav Immun 15:7-24

50. Bodnar CN, Morganti JM, Bachstetter AD (2018) Depression following a traumatic brain injury: uncovering cytokine dysregulation as a pathogenic mechanism. Neural Regen Res 13:1693-1704

51. Wang C, Yue H, Hu Z, Shen Y, Ma J, Li J et al (2020) Microglia mediate forgetting via complement-dependent synaptic elimination. Science 367:688-694

52. Hong S, Beja-Glasser VF, Nfonoyim BM, Frouin A, Li S, Ramakrishnan S et al (2016) Complement and microglia mediate early synapse loss in Alzheimer mouse models. Science 352:712-716

53. Zanier ER, Bertani I, Sammali E, Pischiutta F, Chiaravalloti MA, Vegliante G et al (2018) Induction of a transmissible tau pathology by traumatic brain injury. Brain J Neurol 141:2685-2699

54. Klein RS (2020) On complement, memory, and microglia. N Engl J Med 382:2056-2058

55. Osthoff M, Walder B, Delhumeau C, Trendelenburg M, Turck N (2017) Association of lectin pathway protein levels and genetic variants early after injury with outcomes after severe traumatic brain injury: a prospective cohort study. J Neurotrauma 34:2560-2566

56. Alawieh A, Langley EF, Weber S, Adkins D, Tomlinson S (2018) Identifying the role of complement in triggering neuroinflammation after traumatic brain injury. J Neurosci Off J Soc Neurosci 38:2519-2532

57. Lynch NJ, Khan S-H, Stover CM, Sandrini SM, Marston D, Presanis JS et al (2005) Composition of the lectin pathway of complement in gallus gallus: absence of mannan-binding lectin-associated serine protease-1 in birds. J Immunol 174:4998-5006

\section{Publisher's Note}

Springer Nature remains neutral with regard to jurisdictional claims in published maps and institutional affiliations.
Ready to submit your research? Choose BMC and benefit from:

- fast, convenient online submission

- thorough peer review by experienced researchers in your field

- rapid publication on acceptance

- support for research data, including large and complex data types

- gold Open Access which fosters wider collaboration and increased citations

- maximum visibility for your research: over $100 \mathrm{M}$ website views per year

At BMC, research is always in progress.

Learn more biomedcentral.com/submissions 